\title{
Documentation, communication and follow-up of infant mortality at a tertiary NICU
}

\author{
C Fox $_{1}$, LK McCarthy ${ }_{1}$
}

1. The National Maternity Hospital, Holles St, Dublin, Ireland

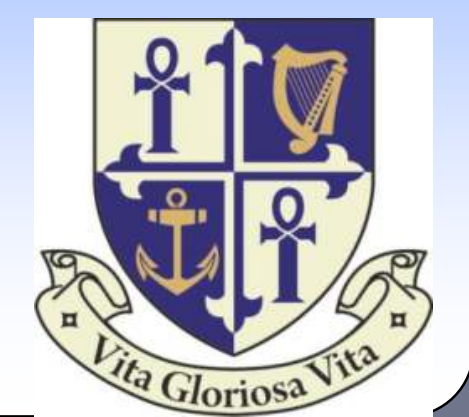

\section{Background and Aims}

- The National Maternity Hospital is a tertiary referral centre with $>9000$ deliveries per year and approx. 120 infants $<1500 \mathrm{~g} / \mathrm{year}$

- Our aims were to review our documentation around neonatal death, our communication with primary care providers; and compare this with our hospital checklist and national standards

\section{Methods}

- Retrospective chart review of all neonatal deaths >23 weeks gestation in 2016 at the $\mathrm{NMH}$

- $\quad$ Patient charts were reviewed for clear documentation of infant death, the cause of death and discussion of post-mortem.

- We recorded if the death notification form had been completed and filed in the infant's chart

- We reviewed documentation of any written or verbal communication with the GP and public health nurse; and if appropriate follow up was arranged

\section{Conclusions}

- Clearer documentation of communication with parents and primary care providers is necessary in our unit

- Our hospital checklist should be updated in line with national guidelines and improvements made to ensure that this is completely filled out

- More than half of the neonatal deaths in 2016 occurred in extremely preterm or ELBW infants

- Almost 1/3 have a PM examination and few are referred to the Coroner.

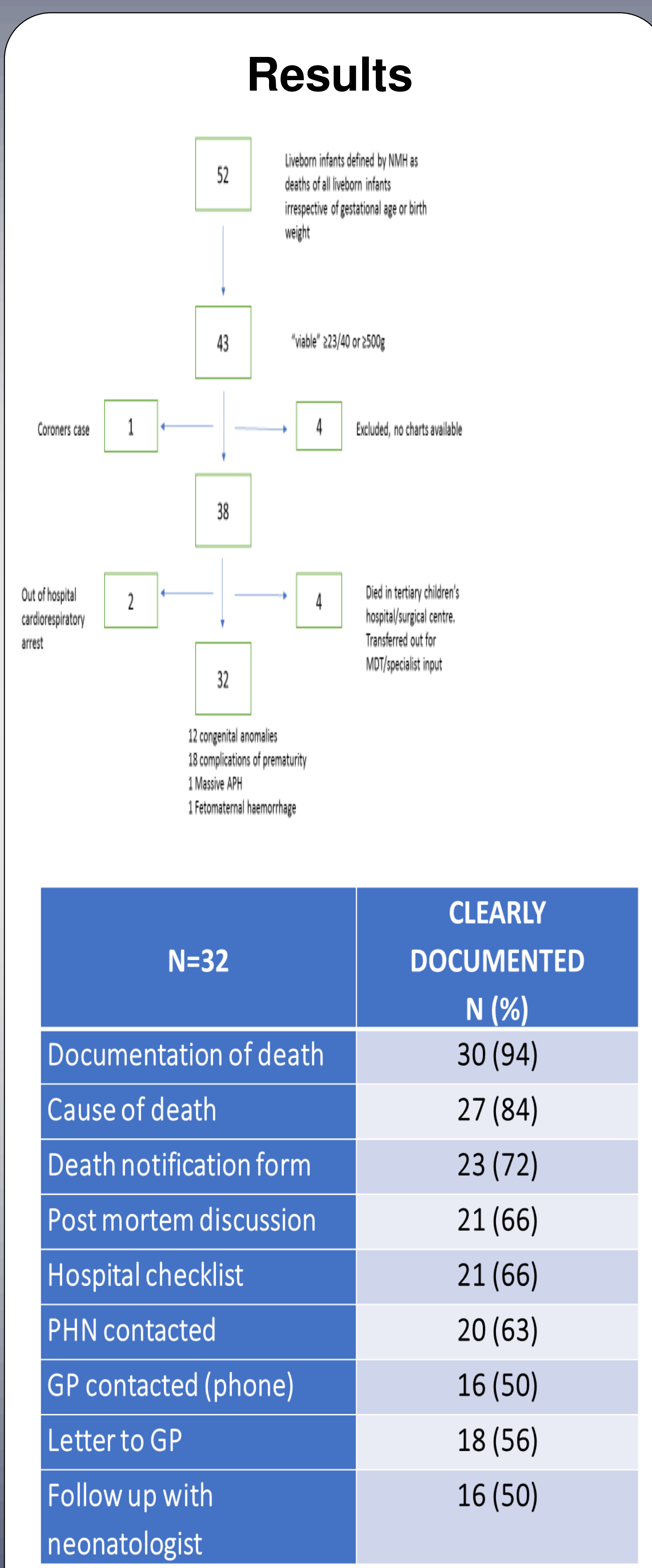

